\title{
Towards cod without spawning: artificial continuous light in submerged sea-cages maintains growth and delays sexual maturation for farmed Atlantic cod Gadus morhua
}

\author{
Øyvind J. Korsøen ${ }^{1,2, *}$, Tim Dempster ${ }^{2,3}$, Jan Erik Fosseidengen ${ }^{1}$, Ørjan Karlsen ${ }^{1}$, \\ Frode Oppedal $^{1}{ }^{\text {, Lars Helge Stien }}{ }^{1}$, Tore S. Kristiansen ${ }^{1}$ \\ ${ }^{1}$ Institute of Marine Research, Austevoll Research Station, 5392 Storebø, Norway \\ ${ }^{2}$ Centre for Research-based Innovation in Aquaculture Technology (CREATE), SINTEF Fisheries and Aquaculture, \\ 7465 Trondheim, Norway
}

${ }^{3}$ Sustainable Aquaculture Laboratory - Temperate and Tropical (SALTT), Department of Zoology, University of Melbourne, Victoria 3010, Australia

\begin{abstract}
Sexual maturation and spawning in sea-cages is a major production and environmental challenge for the Atlantic cod farming industry. Altered photoperiod has arrested sexual maturation in cod kept in indoor or covered experimental tanks, but only delayed or caused asynchronous maturation in cod kept in sea-cages. To arrest the onset of puberty more efficiently, we reduced the relative differences in light intensity between night and day by lowering 4 submersible sea-cages, each stocked with 400 juvenile cod, to $20 \mathrm{~m}$ depth for $14 \mathrm{mo}$. Two cages were continuously illuminated (LL), and 2 cages served as controls with natural light (NL) conditions. Cod grew well in both treatments and showed very low mortality. Final weights did not differ, although the pattern of growth differed through time. Continuous light did not arrest maturation, but delayed it by 3 to 6 mo; gonadosomatic indices reached $21.2 \%$ for NL females during spawning in February to April, but reached only $10.2 \%$ for the LL females over a protracted spawning period from May to September. The liver index for NL fish decreased during spawning by $6 \%$ (females) and $15 \%$ (males). In contrast, the liver index in the LL fish decreased relatively little (females $=5 \%$, males $=3 \%$ ), suggesting these fish invested less energy in maturation. Submergence combined with sufficient artificial lighting will both delay and reduce the extent of maturation, which can improve production strategies through better feed conversion ratios and reduce the risks associated with 'escape through spawning'. Deeper submergence, combined with shading and stronger lighting, may even arrest maturation.
\end{abstract}

KEY WORDS: Photoperiod $\cdot$ Puberty $\cdot$ Gonads $\cdot$ Aquaculture $\cdot$ Spawning

\section{INTRODUCTION}

Sexual maturation is a major production problem during the on-growing phase of Atlantic cod Gadus morhua farming. Both males and females mature in the second winter, 2 yr after hatching, and in some locations a proportion of males mature in the first win-

*Email: oyvind.johan.korsoen@imr.no ter (Karlsen et al. 1995, Davie et al. 2007a). Maturing cod start to reallocate energy from the muscle and liver to gonad growth, and have reduced appetite and growth from 1 mo prior to spawning (Kjesbu 1991, Skjæraasen et al. 2004, Taranger et al. 2006). Thus, maturation and subsequent spawning in seacages represents a significant loss for farmers as en-

() The authors 2013. Open Access under Creative Commons by Attribution Licence. Use, distribution and reproduction are unrestricted. Authors and original publication must be credited. 
ergy is diverted to reproduction rather than somatic growth, resulting in poorer feed conversion ratios and longer production time. Maturation can also lead to increased mortality, particularly for females that fail to release eggs and become 'egg-bound' (Árnason \& Björnsson 2012, Bogevik et al. 2012).

Releases of fertilized eggs from spawning farmed cod may also negatively impact local cod stocks (Jørstad et al. 2008, Uglem et al. 2012). Offspring can intersperse with wild populations as juveniles, recruit to spawning populations and successfully spawn in the wild (van der Meeren et al. 2012). Ecological effects through localised peaks in recruitment may be possible following escape through spawning, as has been suggested for sea bream Sparus aurata farming in the Mediterranean (Dimitriou et al. 2007, Somarakis et al. 2013). Both the production and the environmental problems associated with maturation of cod in sea-cages have led to an increased focus on methods to suppress sexual maturation or limit the likely survival of fertilised gametes released.

At present, the use of continuous light to arrest or delay puberty is the only method available to farmers. In indoor or light-proof tanks, cod readily respond to shifts in photoperiod, and continuous light from the summer solstice onwards arrests sexual maturation for fish growing to around $2.5 \mathrm{~kg}$ wet weight (Hansen et al. 2001, Davie et al. 2007a, de Almeida et al. 2011). In sea-cages floating at the sea surface, similar treatments have not arrested sexual maturation, but have delayed it by 3 to 5 mo (Karlsen et al. 2006, Taranger et al. 2006, Skulstad 2012). Reasons for this discrepancy may be combinations of unpredictable factors, including weather conditions, seasonal light and the night:day ratio, seawater turbidity, and temperature.

Previous experiments using whole tissue cultures have shown that the ability of superimposed light to suppress night-time melatonin production increased with light intensity (Vera et al. 2010). Further, luminance thresholds needed to suppress melatonin secretion in pineal organs in Atlantic cod are affected by previously experienced daylight intensity. This means that reducing the difference between daytime and night-time luminance should improve the efficiency of added continuous light to suppress maturation. Light intensity decreases rapidly with depth in seawater due to scattering and absorption, which varies with salinity, turbidity, and plankton levels.

Combining artificial lights with culture in submerged sea-cages could reduce the relative daylight intensity and suppress gonadal development. Wild cod spend more than $90 \%$ of the time close to the bottom (Hobson et al. 2007), thus the current farming practice of forcing cod towards surface feeding in surface-based 'salmon cages' may not be favourable for production (Kristiansen et al. 2011, Skulstad 2012). Several physoclistous marine species have been successfully farmed in submersible cages (Mediterranean: Mediterranean amberjack Seriola dumerili, Mazzola et al. 2000; seabass Dicentrarchus labrax, Maricchiolo et al. 2011; US: Atlantic cod, Chambers \& Howell 2006). Submersible cages may also be used in more exposed areas and could enable avoidance of a range of surface-related conditions that have negative impacts on production (wind, waves, suboptimal temperature, pathogens, algae, ice; Dempster et al. 2009). Submersible cages could therefore provide welfare benefits for the cod and production benefits to cod farmers.

In this study, we tested whether culturing cod in sea-cages submerged below $20 \mathrm{~m}$ depth with continuous artificial light arrested sexual maturation by comparing results with those in cod held in submerged sea-cages without artificial light. We farmed cod over a 14 mo period from $500 \mathrm{~g}$ to a harvest weight of $3.5 \mathrm{~kg}$ to test the relevance of this method to commercial sea-cage farming.

\section{MATERIALS AND METHODS}

\section{Location and experimental fish}

The experiment was conducted at the Institute of Marine Research, Austevoll Research Station in western Norway $\left(60^{\circ} \mathrm{N}\right)$ from July 2010 until September 2011. Atlantic cod Gadus morhua of a Norwegian coastal strain were farmed at the Institute of Marine Research's seawater pond Parrisvatnet from larvae to $\sim 20 \mathrm{~g}$, and transferred to $125 \mathrm{~m}^{3}$ sea-cages at Austevoll for on-growing. On 1 July, 400 cod were randomly distributed to each of 4 experimental cages that were submerged to $20 \mathrm{~m}$ depth on 9 July 2010 and kept submerged until 1 September 2011.

\section{Submersible cages and light conditions}

The cages were constructed as $5 \times 5 \times 7 \mathrm{~m}$ boxes of white nylon netting (mesh size $20 \mathrm{~mm}$ ) kept spread with aluminium frames at the top (Fig. 1). A submersible lamp was placed $2 \mathrm{~m}$ above the roof of the 2 continuous light (LL) treatment cages. The lamp bulb had a power rating of $400 \mathrm{~W}$ (Powerstar, HQIBT $400 \mathrm{~W} / \mathrm{D}$ colour temperature: $32000 \mathrm{~lm}$, Osram) 
and was lit $24 \mathrm{~h}$ per day. Light intensity was measured between the 2 LL cages at $22.5 \mathrm{~m}$ depth every $15 \mathrm{~min}$ (Fig. 2A) using an underwater spherical quantum sensor LI-193SA connected to an LI-1400 data logger (Li-Cor) that registered the photon flux rate $\left(\mu \mathrm{E} \mathrm{m} \mathrm{m}^{-2} \mathrm{~s}^{-1}\right)$ in the $400-700 \mathrm{~nm}$ range.

The other 2 cages served as controls with only natural light (NL) conditions. The cages were separated horizontally on the farm by a minimum of $40 \mathrm{~m}$ to minimize night-light to the control fish.

Lifting of cages prior to sampling events occurred in 2 steps (20-8 $\mathrm{m}$ and $8-0 \mathrm{~m}$ ) over $48 \mathrm{~h}$ to avoid swim bladder expansion and uncontrolled floating fish. Following sampling, the cages were descended to

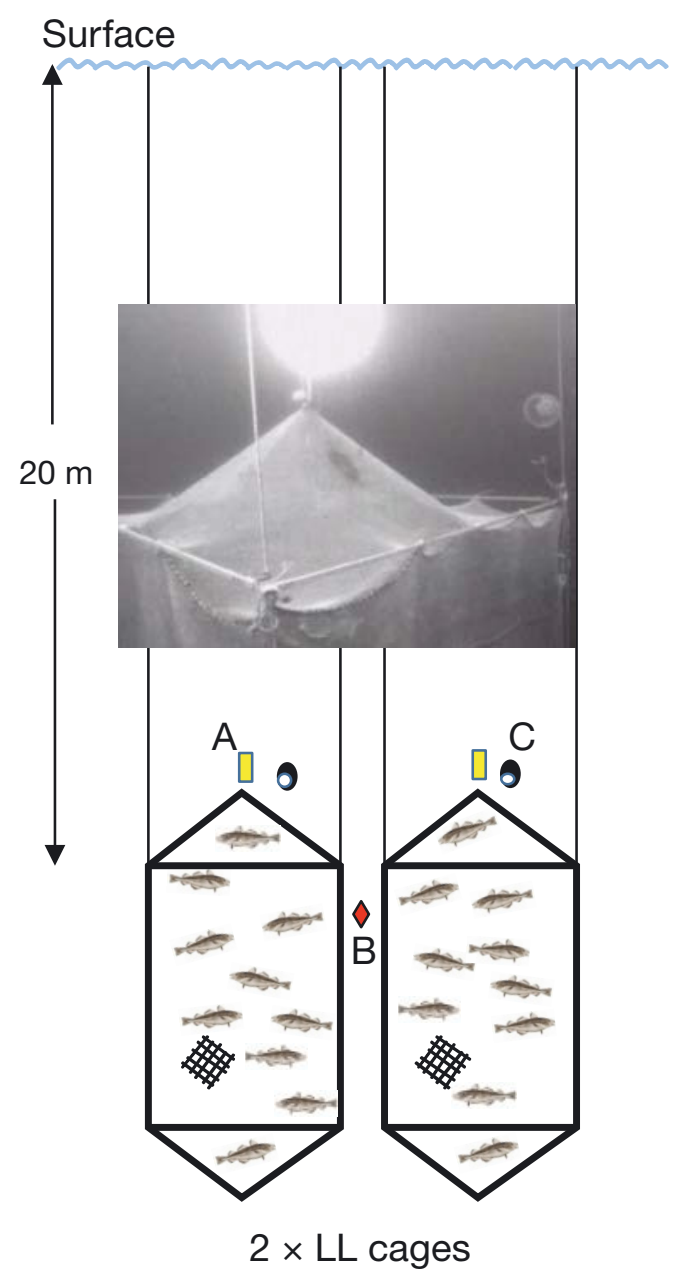

Fig. 1. Experimental setup where Atlantic cod were kept in $5 \times 5 \mathrm{~m}$ wide and $7 \mathrm{~m}$ deep nets with the roof positioned at $20 \mathrm{~m}$ depth. A lamp (A) was placed $1 \mathrm{~m}$ above the roof of each of the 2 neighbouring submerged LL cages (continuously illuminated), and a light sensor (B) hung at $22.5 \mathrm{~m}$ depth between the 2 cages. An underwater camera (C) was positioned close to the lamp to monitor fish feeding activity in each fish group. The photo shows the roof and lamp from one submerged LL cage
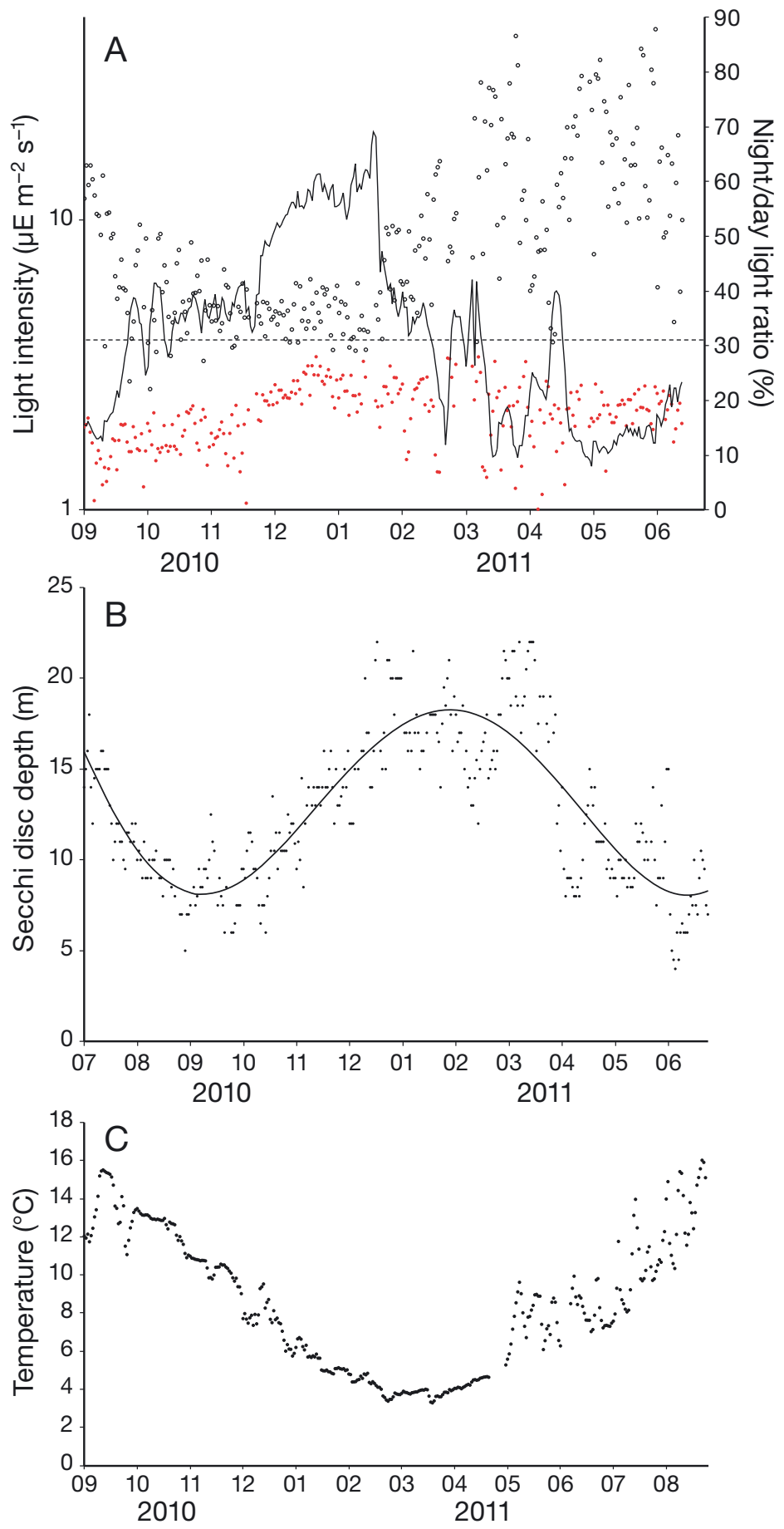

Fig. 2. (A) Daily light intensity at $22.5 \mathrm{~m}$ depth for the continuously illuminated (LL) cages. Daylight is defined from measurements between 11:00 and 14:00 h (open circles) and night-light from 23:00 to 02:00 h (red circles). The horizontal dotted line indicates the recommended $31 \%$ night/day intensity to suppress cod maturation (Cowan et al. 2011), and the black line indicates rolling average of the weekly relationship in the present experiment. (B) Daily measurements of water turbidity during the experimental period. (C) Daily average seawater temperature at $22 \mathrm{~m}$ depth during the experimental period 
the submerged position at $20 \mathrm{~m}$ depth in one operation, all based on procedures for vertical handling of farmed cod developed by Korsøen et al. (2010) and Kristiansen et al. (2011).

\section{Water temperature and turbidity}

At a reference point close to the experimental cages, a CTD (SD204, SAIV AS) measured the water temperature at $22 \mathrm{~m}$ depth every $10 \mathrm{~min}$ during the experimental period (Fig. 2B). Turbidity was estimated daily with a Secchi disc.

\section{Biofouling control}

Nets were not impregnated with antifouling compounds. During each sampling event, the net walls and roof were hung on the cage and sun-dried for approximately $24 \mathrm{~h}$, whereas the net bottom formed a sufficient volume for the fish. Nets were not changed during the 14 mo experiment. Hydroids and mussels grew on the nets during autumn, but disappeared around January 2011.

\section{Feed and feeding}

Feed used during the experiment (Amber Neptun, Skretting, Norway) was of the same type as the fish were given prior to the experiment, and was transported by water through a $20 \mathrm{~m}$ long hose $(4.5 \mathrm{~cm}$ diameter) with an opening fitted immediately below the roof in the centre of the cage. The fish were fed in excess twice daily from 09:00 to 09:30 $\mathrm{h}$ and 14:00 to $14: 30 \mathrm{~h}$ by an automatic feeding system. The feed ration was estimated based on Björnsson et al. (2007), and feeding activity was controlled using an underwater camera (VNSVUC-Z10, Scan Secure AS) mounted $2 \mathrm{~m}$ above the roof of each cage in a fixed position downwards (Fig. 1). Feeding in excess was controlled by observing the fish's response to the pellets at the end of each meal with the underwater camera.

\section{Fish sampling}

The same sampling procedure in each cage was performed at the start of the experiment $\left(t_{0}: 1\right.$ July 2010) and then repeated at 5 time points over 14 mo: $t_{1}$ : 22 November $2010 ; t_{2}$ : 23 February $2011 ; t_{3}$ : 3 May
$2011 ; t_{4}: 29$ June 2011; and $t_{5}: 1$ September 2011. The fish were crowded and a random sample of 50 fish was netted from each cage. For each fish, we recorded length (resolution $1 \mathrm{~cm}$ ), wet weight (not bled), gutted weight, liver weight, gonad weight (all resolution $1 \mathrm{~g}$ ), and sex, while sexual maturation was also determined visually (based on Sivertsen 1935). For females, a sample of the ovary was fixed in $3.7 \%$ phosphate buffered formaldehyde in saline for subsequent analysis of sexual maturation.

Specific growth rate $\left(\% \mathrm{~d}^{-1}\right)$ was calculated as $\left(\mathrm{e}^{q}-1\right)$ $\times 100$, where $q=\left(\ln \left[W_{2}\right]-\ln \left[W_{1}\right]\right)\left(t_{2}-t_{1}\right)^{-1}$, and $W_{2}$ and $W_{1}$ are the wet body weights at end and start of each sampling interval, respectively. Fulton's condition factor $(K)$ was calculated as $K=\left(W L^{-3}\right) \times 100$, where $W$ is the wet weight $(\mathrm{g})$ and $L$ is the length (cm). Gonadosomatic (GSI) and liver (hepatosomatic, HSI) indices were calculated as percent organ weight of wet weight.

\section{Sexual maturation}

Ovary samples were used to determine the stage of maturity based on the size of the leading cohort of oocytes. Oocyte sizes were photographed and the diameter of vitellogenic oocytes was automatically measured using an image analysis system (Thorsen \& Kjesbu 2001). A correction factor of $5 \%$ shrinkage of oocytes in formalin prior to measurements was applied (Svåsand et al. 1996). Ovaries were classified according to the size of the leading cohort of oocytes (G1 diameter) as immature/regressing $(<239 \mu \mathrm{m})$, cortical alveoli (240-369 $\mu \mathrm{m})$, early vitellogenic (370$439 \mu \mathrm{m})$, late vitellogenic (440-869 $\mu \mathrm{m})$, spawning $(>870 \mu \mathrm{m})$, or spent (based on visual inspection of oocytes) adapted from Kjesbu (1991) and Dahle et al. (2003). In addition, subsamples from the last sample from the LL cages were embedded in paraffin, sectioned, and analysed for the appearance of post ovulatory follicles, as this can be used to determine whether the females had spawned earlier in the season. The number of egg-bound fish were recorded and were defined as dead or sampled females with extremely large gonads (>30\% GSI).

\section{Statistical analyses}

Effects of light treatment (LL or NL) on measured mean weight, GSI, HSI, and $K$-factor were investigated using mixed-effects models (Pinheiro \& Bates 2000), with light treatment and sex as fixed effects 
and cage as a random effect (function lme in R). Prior to analysis, data on body weight, GSI, HSI, and $K$ were checked for normal distribution using a normal distribution plot. To adjust for eventual different variances by sex for the within-group error, a variance function (varIdent) was used in the analyses (Pinheiro \& Bates 2000).

\section{RESULTS}

\section{Light intensity and water temperature}

Light intensity at the measuring point near the submerged LL cages at night was fairly constant throughout the experiment, averaging $2.1 \pm 0.0 \mu \mathrm{E}$ $\mathrm{m}^{-2} \mathrm{~s}^{-1}$ (mean $\pm \mathrm{SE}$; Fig. 2A). During daytime, light levels varied seasonally, with average levels of $5.9 \pm$ $0.1 \mu \mathrm{E} \mathrm{m}^{-2} \mathrm{~s}^{-1}$ from September 2010 to January 2011,

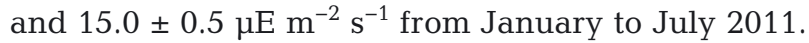
This seasonal change led to a major shift in the relationship between night-time and daytime light intensity, with night-time intensity exceeding $30 \%$ of daytime levels from mid-September 2010 to mid-January 2011 and around $15 \%$ after. In the NL cages, the daytime levels followed the natural intensity pattern, i.e. similar levels as LL cages at day (natural intensity always exceeded artificial levels), and complete darkness at night. Visibility followed a normal seasonal pattern with least turbidity during winter (Fig. 2B). Water temperatures at $22 \mathrm{~m}$ depth followed a normal seasonal pattern and ranged from 3.3 to 16.5 ${ }^{\circ} \mathrm{C}$ (Fig. 2C).

\section{Development of sexual maturation}

Visual appearance, gonad size, and ovary classification based on oocyte diameters indicate that all fish of both sexes held under NL conditions entered puberty in autumn 2010, and spawned in winter to spring 2011. All NL females showed G1 oocyte diameters above $300 \mu \mathrm{m}$ in November 2010 (Fig. 3). GSIs of NL fish in November were $2.4 \pm 0.2 \%$ and $3.7 \pm 0.3 \%$ for females and males, respectively, significantly higher than those of the LL fish (females: $0.7 \pm 0.0 \%$, males $0.2 \pm 0.0 \%, \mathrm{p}<0.001$ ) for both sexes (Fig. 4).

In February 2011, about 50 NL females were spawning, as indicated by hyaline oocytes, while the remaining fish were in the late vitellogenic stage. All NL males showed running testes. GSIs were $21.1 \pm$ $0.8 \%$ and $8.4 \pm 0.7 \%$ for females and males, respec-

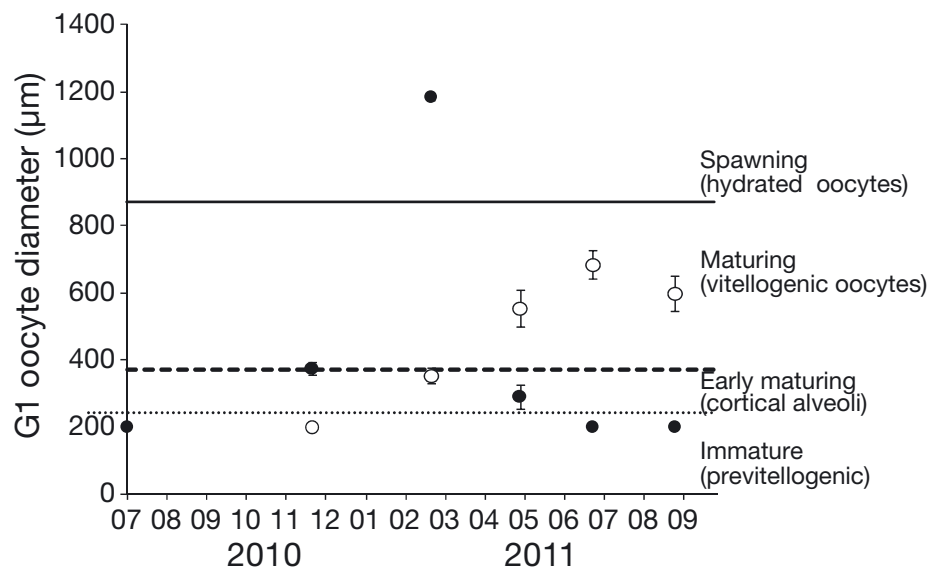

Fig. 3. Gadus morhua. Mean $( \pm \mathrm{SE})$ diameter of the leading cohort of oocytes (G1 diameter) of individual females from each sample time for continuous illumination (LL; open circles) and natural light (NL, filled circles) treated fish $(\mathrm{n}=53$ to 61 fish), classified as immature/regressing $(<239 \mu \mathrm{m})$, cortical alveoli $(240-369 \mu \mathrm{m})$, early vitellogenic $(370-439 \mu \mathrm{m})$, late vitellogenic $(440-869 \mu \mathrm{m})$, spawning $(>870 \mu \mathrm{m})$, or spent (adapted from Kjesbu 1991, Dahle et al. 2003)

tively. LL fish remained relatively immature; $75 \%$ of fish showed development varying from the cortical alveoli stage to one spawning female. This was confirmed by analysis of G1 oocyte diameters. GSIs were $1.6 \pm 0.1 \%$ (females) and $1.5 \pm 0.2 \%$ (males), significantly lower than those of the NL fish $(p<0.001)$.

In May, most of the NL females had regressing gonads, only a few were still spawning, and GSIs were $2.4 \pm 0.4 \%$ (females) and $0.5 \pm 0.0 \%$ (males). In contrast, in the LL group, the number of immature fish was low, since many were in the earlier stages of maturation, with ovaries in the cortical alveoli and early vitellogenic stage. Gonads had grown; GSIs were $4.6 \pm 0.6 \%$ (females) and $3.6 \pm 0.3 \%$ (males).

By late June, NL females showed regressing gonads, with the presence of mostly previtellogenic oocytes and a relatively low number of atretic oocytes, with GSI at $1.3 \pm 0.1 \%$ (females) and $0.4 \pm$ $0.0 \%$ (males). In contrast, about $90 \%$ of the LL females showed ovaries in the late vitellogenic stage or were spawning, with GSIs of $6.3 \pm 0.6 \%$ (females) and $4.4 \pm 0.4 \%$ (males).

In early September, the NL females showed only previtellogenic oocytes, while most of the LL fish showed spent gonads, with GSIs of $4.6 \pm 0.6 \%$ (females) and $1.7 \pm 0.3 \%$ (males). Histological examinations of 16 representative gonads from the LL group showed that 14 of these had post ovulatory follicles, indicating they had spawned earlier in the season. Of the 2 remaining fish, one was in late vitellogenic stage. 

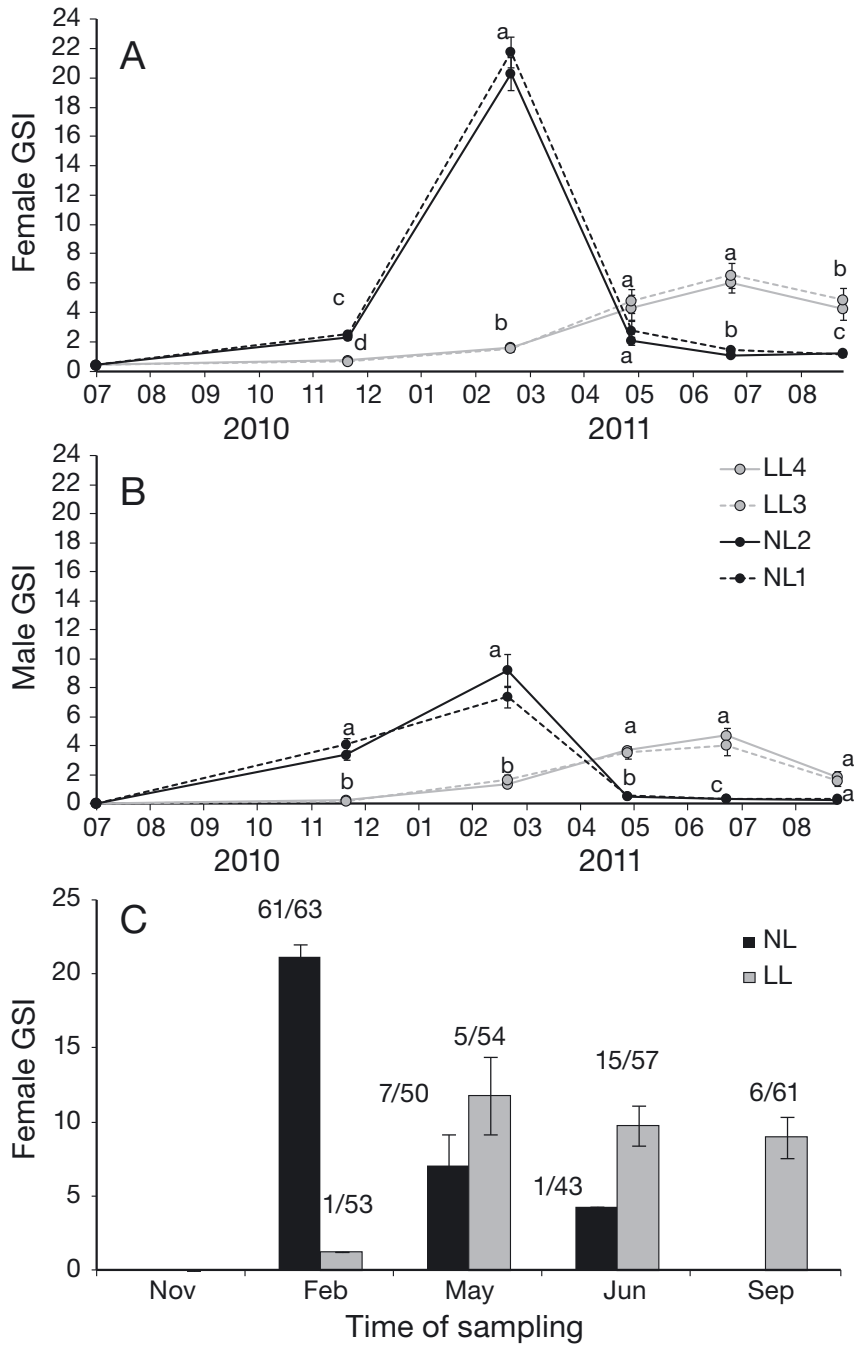

Fig. 4. Gadus morhua. Gonadosomatic index (GSI; mean \pm $\mathrm{SE}$ ) for female (A) and male cod (B) from each continuous illumination (LL) and natural light (NL) cage for 50 fish from 6 samplings during the experimental cycle. Letters in $(\mathrm{A}, \mathrm{B})$ indicate a significant difference between sex and treatments $(p<0.05)$. (C) GSI for females, classified as number of spawners/total number of females in the sample $(>1100 \mu \mathrm{m}$ G1 oocyte diameter, e.g. 61 females were spawners out of $63 \mathrm{fe}-$ males in the NL group in February with a GSI of $21.2 \pm 0.8$ )

\section{Investment in reproduction}

The relative gonad sizes for the LL females did not reach levels similar to those of the NL females (Fig. 4C). By comparing the GSI of NL and LL fish at the same developmental stage, it appears that the mean GSI of NL females in the late vitellogenic and spawning stages were $21.2 \pm 0.8 \%(\mathrm{n}=61)$ in February and $7.0 \pm 2.4 \%(\mathrm{n}=7)$ in May. In comparison, the LL females had GSI levels of $11.8 \pm 2.6 \%(\mathrm{n}=5), 9.8 \pm$ $1.3 \%(\mathrm{n}=15)$, and $8.9 \pm 1.4 \%(\mathrm{n}=6)$ in May, June, and September, respectively.
The liver index (HSI) and $K$-factor were affected by light regime and sex (Fig. 5). Given natural light, the liver index for females and males decreased by $6 \%$ and $15 \%$, respectively, during puberty and spawning (November to May), with a subsequent increase of $30 \%$ for females and $34 \%$ for males until September. Accordingly, condition increased for these fish as they developed gonads during puberty and up until spawning, while male condition decreased slightly as they invested in testes.

In the LL fish, the same patterns as for NL fish were evident in liver index and condition; however, they were delayed, had less pronounced peaks, and variation between sexes was reduced. During spawning, HSI declined by $5 \%$ for females (May to September) and $3 \%$ for males (May to June). Peak condition for females was lower ( $K=1.47$ in June) than the NL females (1.57 in February). Males in both NL and LL groups varied less than the females (range: 1.20 to 1.38).
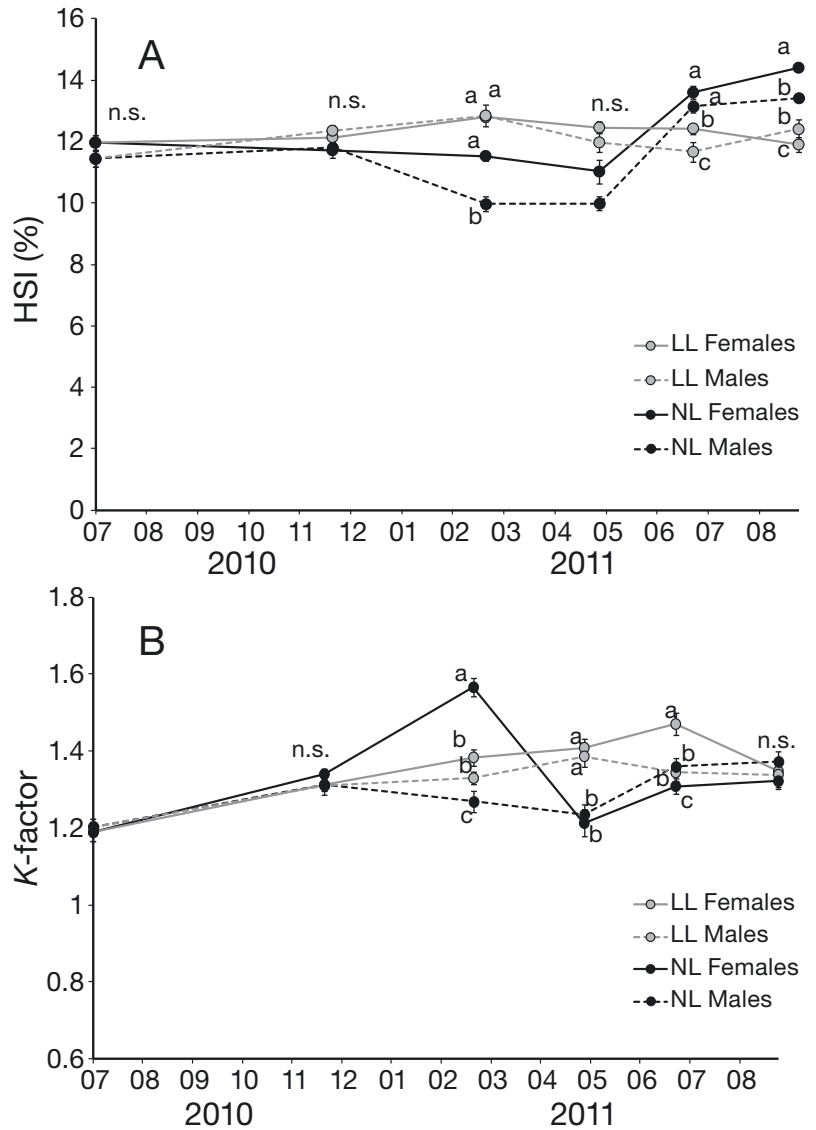

Fig. 5. Gadus morhua. (A) Hepatosomatic index (HSI; mean \pm SE) and (B) $K$-factor for female and male cod from continuous illumination (LL) and natural light (NL) cages. Letters indicate a significant difference between sex and treatments $(\mathrm{p}<0.05)$; n.s.: not significant 


\section{Growth performance}

The fish adapted rapidly to the submerged seacages, growing from 600 to $1400 \mathrm{~g}$ from July to November 2010, with no significant difference between treatments (Fig. 6A,B). From November 2010 until the end of February 2011, the LL fish grew nearly linearly, while NL females lost weight $(4.3 \%)$ and NL males maintained their body weight (Fig. 6C,D). In early May, LL fish $(2.39 \pm 0.05 \mathrm{~kg})$ were 1.4 times heavier than NL fish $(1.74 \pm 0.04 \mathrm{~kg}$, $\mathrm{p}=0.03$ ). During the summer, the NL fish, having finalised their spawning, showed compensatory growth, whereas a long and unsynchronised spawning period with reduced growth took place for the LL fish. This resulted in similar mean final weights in September: LL $=3.24 \pm 0.08 \mathrm{~kg}$ and $\mathrm{NL}=$ $3.14 \pm 0.06 \mathrm{~kg}(\mathrm{p}=0.12)$. The males in both treat- ments grew slower than the females during the first 10 mo of the experiment, but weights at harvest did not differ between sexes, independent of treatment (gutted weight: LL males $=2.60 \mathrm{~kg}$, females = $2.62 \mathrm{~kg}$; NL males $=2.59 \mathrm{~kg}$, females $=2.58 \mathrm{~kg}, \mathrm{p}=$ 0.85; Fig. 6C,D).

\section{Incidence of egg-bound females, mortality and general condition}

Egg-bound females were not found in any of the spawning fish sampled. Over the 14 mo experiment, 6 fish died in each treatment, giving a mortality rate of $1.5 \%$. General condition of the cod in both the NL and LL treatment cages based on their visual appearance was good. Skin, fins, and snouts had no visible signs of wear or wounds.
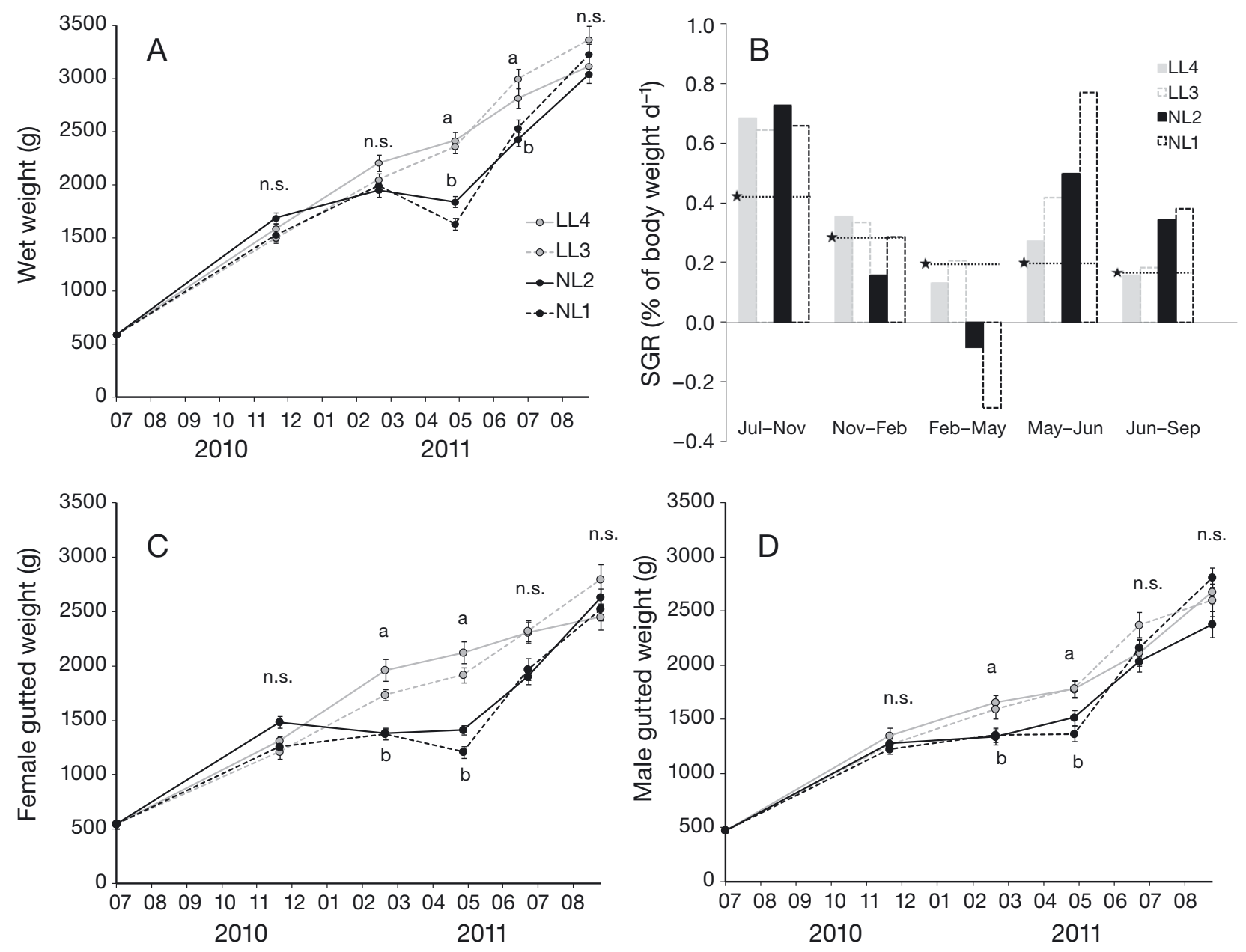

Fig. 6. Gadus morhua. (A) Mean ( \pm SE) wet weight, (B) specific growth rate (SGR), and (C) female and (D) male gutted weight of cod exposed to natural light (cages NL1 and NL2) or continuous light (cages LL3 and LL4) from 9 July 2010 to 1 September 2011. Letters indicate a significant difference between treatments $(\mathrm{p}<0.05)$; n.s.: not significant. In (B) the star and dotted line indicate estimated growth rates at similar body weight and temperature, based on Björnsson et al. (2007) 


\section{DISCUSSION}

\section{Effects on sexual maturation}

While the combination of continuous artificial light and the reduced incidence of light from the surface by submerging sea-cages to below 20 m did not completely arrest the sexual maturation of Atlantic cod, the phase of maturation was more uniformly delayed for all the cod compared with other sea-cage experiments that used surface-based cages and similar artificial light regimes (Karlsen et al. 2006, Taranger et al. 2006, Skulstad 2012). In contrast, submergence without artificial light led to cod maturing in a synchronised manner in February/March, likely driven by the seasonal changes in light levels and other environmental variables, which typically lead to maturation of both wild and farmed Atlantic cod in the spring spawning period in western Norway (Kjesbu \& Kryvi 1989, Berg \& Albert 2003, Taranger et al. 2006).

GSI levels in the late vitellogenic and spawning stage were much greater in the NL females than the LL females, which had significantly smaller gonads. While we do not understand the mechanisms that drove this difference, the difference itself strongly suggests that fewer eggs were spawned by LL fish compared with the NL fish. Fewer fertilised eggs may therefore have resulted from this out-of-season spawning. Altered photoperiod also resulted in less energy investment in reproduction for LL fish, with smaller gonads and less variation in liver weights and condition, suggesting that production with continuous lights could improve feed conversion ratios. Maturation and spawning results in a large weight loss, and loss of growth due to reduced appetite (e.g. Karlsen et al. 1995, Dahle et al. 2003), but fish do show a compensatory growth (also seen in HSI) after maturation (Pedersen \& Jobling 1989). The LL group does not show such fluctuations, and we never observed such large gonads as seen in the NL group. Even though the LL group may be less synchronised, the data strongly indicate that the maximum GSI is much lower in the LL group. While we do not have good feed conversion data, we added in total $4 \%$ more feed to the NL cages (1685 kg for NL versus $1615 \mathrm{~kg}$ for LL).

Cod are more sensitive to the ratio of the natural day to night light intensities rather than the absolute levels of light delivered by artificial lights at night (Vera et al. 2010). Based on results from cod in shaded outdoor tank experiments, Cowan et al. (2011) recommended that night-time luminance should exceed $31 \%$ of the daytime light levels. In our experiment, the night/day level was around 36\% for the first $6 \mathrm{mo}$, but only $15 \%$ during winter and spring (Fig. 2A). The reduced night/day level after early February 2011 was probably due to increasing sun height, less surface reflection of incoming light (Sakshaug et al. 1994), and therefore higher light penetration into the water. The LL fish may therefore have experienced a belated 'autumn signal' that initiated the maturation process.

In future experimental work, improved light conditions at night could be achieved by placing light sources inside the cage volume, and providing multiple lamps and/or lamps with higher intensities. Furthermore, adjustment of light intensity relative to the daylight intensity that takes into account seasonal changes in incident natural light levels may prove beneficial. More efficient dimming of daylight may also be achieved through shaded netting in the roof (e.g. Huse et al. 1990, Cowan et al. 2011). These changes would lessen differences between night and day levels, but to lower the daylight most efficiently, cages should be descended deeper than 20 m, especially from February onwards.

Other environmental parameters may also have interrupted the development of puberty. Temperature directly affects metabolic processes and reproductive investment (Morgan et al. 2010, Taranger et al. 2010), and could therefore have contributed to synchronising the physiological rhythms of reproduction we observed.

\section{Effects on growth and mortality}

Cod in both natural and artificial light groups had high growth rates and low mortality levels, and no egg-bound females were observed. The growth rate for the LL-treated fish (Fig. 6B) was higher than or similar to expected growth rates for farmed cod established by Björnsson et al. (2007). Similar growth has previously been observed for cod in surfacebased cages with similar experimental conditions (photoperiod, temperature, and food availability; Taranger et al. 2006). In contrast, NL groups in several experiments in surface-based sea-cages have grown significantly slower than LL groups (seacages: Taranger et al. 2006; tanks: Hansen et al. 2001, Davie et al. 2007b, Cowan et al. 2011). In comparison, the present NL fish exhibited strong compensatory growth during the summer, which led to similar average harvest weights $(3.2 \mathrm{~kg})$ as the LL fish. Rapid compensatory growth after spawning has 
been shown in previous sea-cage experiments, although not in direct comparison to LL-treated groups of cod (Jobling et al. 1994, Solberg \& Willumsen 2008). No differences in final weight were found between LL males and females, which contrasts to findings by Davie et al. (2007b) and Cowan et al. (2011), where females were 11 to $40 \%$ larger than the males. Thus, our results indicate submerged seacages provided good growth conditions for cod independent of light treatments.

The negligible mortality and absence of females with egg-bound problems emphasises these possible beneficial rearing conditions. Other studies of farmed cod, albeit at higher stocking densities than in our experiment, have reported significant female mortality rates during the spawning period in tanks and sea-cages (up to $36 \%$; e.g. Árnason \& Björnsson 2012). Further research should test whether submerged cage culture at the higher densities typical of commercial culture would also avoid the production of egg-bound females and mortality.

\section{Submergence and artificial lights as a strategy to improve production and reduce ecological effects of escape through spawning}

The use of submersible cages and altered photoperiods opens new possibilities for improved production strategies that differ from current surfacebased farming. Rapid growth and harvest before spawning would minimise economic losses incurred due to spawning and the amount of feed used. Delayed spawning, as for the LL group in this experiment, led to cod around $0.7 \mathrm{~kg}$ heavier than NL fish (2.4 versus $1.7 \mathrm{~kg}$ ) in early May. Farming the cod in submersible cages and following (by descending/ascending) the optimal temperature and depth during winter and spring will shorten the time to reach harvest weight. Wild ArctoNorwegian cod experience higher temperatures during winter and spring than during summer and autumn, due to horizontal and vertical migration in the Barents Sea (Godø \& Michalsen 2000). The temperature in the Barents Sea is relatively stable at depths greater than $100 \mathrm{~m}$ (Brander 2005). For example, an estimated harvest weight of $3.5 \mathrm{~kg}$ could be achieved from an initial weight at $0.6 \mathrm{~kg}$ with a constant temperature of $8^{\circ} \mathrm{C}$ (which is warmer than in the present experiment) from July until the following June, based on growth rates around 0.4 to $0.6 \%$ of body weight per day (Björnsson et al. 2007).
Even if farmers do not follow a production strategy to maximize growth and harvest fish before sexual maturation, the use of submerged sea-cages and artificial lights can delay spawning until summer. Cod eggs would therefore be spawned and larvae produced at a time of year that is sub-optimal for larval survival, producing a possible mismatch between cod larvae and the planktonic larval feeds they require. The spawning period of wild cod has evolved to concentrate in the window from February to May (Kjesbu \& Kryvi 1989, Berg \& Albert 2003), which coincides with the growth period of the nauplii of Calanus finmarchicus, one of the major prey items for cod larvae. Thus, temporal mismatch between cod larvae and prey and poor larval survival are far more likely for farmed cod spawned in summer (Uglem et al. 2012). In addition, cod larvae have an upper thermal tolerance of around $12^{\circ} \mathrm{C}$ (Geffen et al. 2006), which was exceeded in the submerged cages from early July until September and may be exceeded in coastal waters in summer more broadly where cod farming occurs.

\section{CONCLUSIONS}

Submergence below $20 \mathrm{~m}$ depth together with artificial illumination was not sufficient to arrest maturation, but delayed maturation by 3 to 6 mo and reduced the overall energetic investment into spawning. The high growth and low mortality rates from the present experiment indicate good welfare for the cod in the submerged cages, independent of photoperiod. Submerged fish farms may therefore be an improved method for farming Atlantic cod. Further production advantages through altering photoperiod to arrest sexual maturation are likely. Future studies involving submersible cages should test whether the combination of shading the cage roof, increasing light levels inside cages, and deeper position of cages achieve the recommended $31 \%$ night/day light ratio (Cowan et al. 2011), and fully arrest sexual maturation in the sea. In addition, research should be undertaken to better understand the causes and consequences of other factors that may influence maturation, including fluctuations in seawater temperature.

Acknowledgements. Thanks to the staff at Austevoll Research Station for skilful farming prior to the experiment. All experimental protocols complied with the Norwegian ethical standards for research involving animals. Funding was provided by the Research Council of Norway through the Centre for Research Innovation in Aquaculture Technology (CREATE) and the Department of Fisheries and Coastal Affairs. 


\section{LITERATURE CITED}

Árnason T, Björnsson B (2012) Spawning-related mortality in captive Atlantic cod (Gadus morhua L.). Aquacult Res 43:292-296

Berg E, Albert OT (2003) Cod in fjords and coastal waters of North Norway: distribution and variation in length and maturity at age. ICES J Mar Sci 60:787-797

Björnsson B, Steinarsson A, Árnason T (2007) Growth model for Atlantic cod (Gadus morhua): effects of temperature and body weight on growth rate. Aquaculture 271: 216-226

Bogevik AS, Natário S, Karlsen Ø, Thorsen A, Hamre K, Rosenlund G, Norberg B (2012) The effect of dietary lipid content and stress on egg quality in farmed Atlantic cod Gadus morhua. J Fish Biol 81:1391-1405

Brander K (2005) Spawning and life history information for North Atlantic cod stocks. ICES Coop Res Rep 274:1-152

Chambers M, Howell WH (2006) Preliminary information on cod and haddock production in submerged cages off the coast of New Hampshire, USA. ICES J Mar Sci 63: 385-392

> Cowan M, Davie A, Migaud H (2011) The effect of combining shading and continuous lighting on the suppression of sexual maturation in outdoor-reared Atlantic cod, Gadus morhua. Aquaculture 320:113-122

> Dahle R, Taranger GL, Karlsen Ø, Kjesbu OS, Norberg B (2003) Gonadal development and associated changes in liver size and sexual steroids during the reproductive cycle of captive male and female Atlantic cod (Gadus morhua L.). Comp Biochem Physiol A 136:641-653

> Davie A, Porter MJR, Bromage NR, Migaud H (2007a) The role of seasonally altering photoperiod in regulating physiology in Atlantic cod (Gadus morhua). I. Sexual maturation. Can J Fish Aquat Sci 64:84-97

> Davie A, Porter MJR, Bromage NR, Migaud H (2007b) The role of seasonally altering photoperiod in regulating physiology in Atlantic cod (Gadus morhua). II. Somatic growth. Can J Fish Aquat Sci 64:98-112

de Almeida FFL, Andersson E, Mittelholzer C, Karlsen $\varnothing$, Taranger GL, Schulz RW (2011) Pituitary gonadotropin and testicular gonadotropin receptor expression in Atlantic cod (Gadus morhua L.) during the first reproductive season: effects of photoperiod modulation. Gen Comp Endocrinol 173:111-119

> Dempster T, Korsøen Ø, Folkedal O, Juell JE, Oppedal F (2009) Submergence of Atlantic salmon (Salmo salar) in sea-cages: a potential short-term solution to poor surface conditions. Aquaculture 288:254-263

> Dimitriou E, Katselis G, Moutopoulos DK, Akovitiotis C, Koutsikopoulos C (2007) Possible influence of reared gilthead sea bream (Sparus aurata, L.) on wild stocks in the area of the Messolonghi lagoon (Ionian Sea, Greece). Aquacult Res 38:398-408

Geffen AJ, Fox CJ, Nash RDM (2006) Temperature-dependent development rates of cod Gadus morhua eggs. J Fish Biol 69:1060-1080

Godø OR, Michalsen K (2000) Migratory behavior of northeast Arctic cod, studied by use of data storage tags. Fish Res 48:127-140

> Hansen T, Karlsen $\varnothing$, Taranger GL, Hemre GI, Holm JC, Kjesbu OS (2001) Growth, gonadal development and spawning time of Atlantic cod (Gadus morhua) reared under different photoperiods. Aquaculture 203:51-67

> Hobson VJ, Righton D, Metcalfe JD, Hays GC (2007) Verti- cal movements of North Sea cod. Mar Ecol Prog Ser 347: $101-110$

Huse I, Bjordal Å, Fernö A, Furevik D (1990) The effect of shading in pen rearing of Atlantic salmon (Salmo salar). Aquacult Eng 9:235-244

Jobling M, Meloy OH, dos Santos J, Christiansen B (1994) The compensatory growth response of the Atlantic cod: effects of nutritional history. Aquacult Int 2:75-90

Jørstad KE, van der Meeren T, Paulsen OI, Thomsen T, Thorsen A, Svåsand T (2008) 'Escapes' of eggs from farmed cod spawning in net pens: recruitment to wild stocks. Rev Fish Sci 16:285-295

Karlsen Ø, Holm JC, Kjesbu OS (1995) Effects of periodic starvation on reproductive investment in first-time spawning Atlantic cod (Gadus morhua). Aquaculture 133:159-170

> Karlsen Ø, Hemre GI, Tveit K, Rosenlund G (2006) Effect of varying levels of macro-nutrients and continuous light on growth, energy deposits and maturation in farmed Atlantic cod (Gadus morhua L.). Aquaculture 255: 242-254

Kjesbu OS (1991) A simple method for determining the maturity stages of Northeast Arctic cod (Gadus morhua L.) by in vitro examination of oocytes. Sarsia 75:335-338

Kjesbu OS, Kryvi H (1989) Oogenesis in cod Gadus morhua L., studied by light and electron microscopy. J Fish Biol 34:735-746

Korsøen ØJ, Dempster T, Fosseidengen JE, Fernö A, Heegaard E, Kristiansen TS (2010) Behavioural responses to pressure changes in cultured Atlantic cod (Gadus morhua): defining practical limits for submerging and lifting sea-cages. Aquaculture 308:106-115

Kristiansen TS, Stien LH, Fosseidengen JE, Strand E, Juell JE (2011) Voluntary responses and limits of tolerance to pressure reduction and swimbladder expansion in farmed Atlantic cod. Aquacult Int 19:625-636

Maricchiolo G, Mirto S, Caruso G, Caruso T and others (2011) Welfare status of cage farmed European sea bass (Dicentrarchus labrax): a comparison between submerged and surface cages. Aquaculture 314:173-181

Mazzola A, Favaloro E, Sarà G (2000) Cultivation of the Mediterranean amberjack, Seriola dumerili (Risso, 1810), in submerged cages in the Western Mediterranean Sea. Aquaculture 181:257-268

> Morgan MJ, Rideout RM, Colbourne EB (2010) Impact of environmental temperature on Atlantic cod Gadus morhua energy allocation to growth, condition and reproduction. Mar Ecol Prog Ser 404:185-195

Pedersen T, Jobling M (1989) Growth rates of large, sexually mature cod, Gadus morhua, in relation to condition and temperature during an annual cycle. Aquaculture 81: 161-168

Pinheiro JC, Bates DM (2000) Mixed-effects models in S and S-PLUS. Springer, New York, NY

Sakshaug E, Bjørge A, Gulliksen B, Loeng H, Mehlum F (1994) Økosystem barentshavet. Mesna-Trykk As, Lillehammer (in Norwegian)

Sivertsen E (1935) The cod's spawning. The yearly variation of the maturation stages of the gonads. Fiskeridirektoratets Skrifter, Serie Havundersøkelser 4:1-29 (in Norwegian)

Skjæraasen JE, Salvanes AGV, Karlsen Ø, Dahle R, Nilsen T, Norberg B (2004) The effect of photoperiod on sexual maturation, appetite and growth in wild atlantic cod (Gadus morhua L.). Fish Physiol Biochem 30:163-174

Skulstad OF (2012) Effects of photoperiod manipulation on 
behavior and sexual maturation in farmed Atlantic cod (Gadus morhua L.), production and welfare implications. PhD thesis, University of Bergen, AIT Oslo AS, Oslo

Solberg C, Willumsen L (2008) Difference in growth and chemical composition between male and female farmed cod (Gadus morhua) throughout a maturation cycle. Aquacult Res 39:619-626

Somarakis S, Pavlidis M, Saapoglou C, Tsigenopoulos CS, Dempster T (2013) Evidence for 'escape through spawning' in large gilthead sea bream Sparus aurata reared in commercial sea-cages. Aquacult Environ Interact 3: 135-152

Svåsand T, Jørstad KE, Otterå H, Kjesbu OS (1996) Differences in growth performance between Arcto-Norwegian and Norwegian coastal cod reared under identical conditions. J Fish Biol 49:108-119

Taranger GL, Aardal L, Hansen T, Kjesbu OS (2006) Continuous light delays sexual maturation and increases growth of Atlantic cod (Gadus morhua L.) in sea cages. ICES J Mar Sci 63:365-375

Editorial responsibility: Dean Jerry,

Townsville, Queensland, Australia
Taranger GL, Carrillo M, Schulz RW, Fontaine P and others (2010) Control of puberty in farmed fish. Gen Comp Endocrinol 165:483-515

Thorsen A, Kjesbu OS (2001) A rapid method for estimation of oocyte size and potential fecundity in Atlantic cod using a computer-aided particle analysis system. J Sea Res 46:295-308

Uglem I, Knutsen Ø, Kjesbu OS, Hansen ØJ and others (2012) Extent and ecological importance of escape through spawning in sea-cages for Atlantic cod. Aquacult Environ Interact 3:33-49

van der Meeren T, Jørstad KE, Paulsen OI, Dahle G (2012) Offspring from farmed cod (Gadus morhua L.) spawning in net pens: documentation of larval survival, recruitment to spawning stock, and successful reproduction. ICES CM 2012/P:11

> Vera LM, Davie A, Taylor JF, Migaud H (2010) Differential light intensity and spectral sensitivities of Atlantic salmon, European sea bass and Atlantic cod pineal glands ex vivo. Gen Comp Endocrinol 165:25-33

Submitted: December 20, 2012; Accepted: April 2, 2013 Proofs received from author(s): May 16, 2013 